\title{
Correspondence
}

\section{Medical care in severe mental handicap}

Sir,

I wholeheartedly support Dr MacFaul's plea for continuation of National Health Service treatment facilities as a necessary back up to community care now that mental handicap hospitals are closing their doors. ${ }^{1}$ Time and again one comes across situations requiring prolonged admission to the ward because of relapse in fit control, severe feeding difficulties, severe respiratory infection, deterioration in behaviour, and also emergency admission for short term respite care when social service provision fails, as it is more geared to planned placement. We try to cope with these problems in the acute paediatric ward, which is so busy dealing with acutely ill children that adequate observation and management of the handicapped child is considerably compromised.

While agreeing with Dr MacFaul that the paediatric department of a district general hospital has a role in the management of these children, it is necessary to point out that extra facilities will be required in the way of appropriate ward accommodation and nursing staff who have the appropriate skills. Such a unit (probably not more than 10 beds in size) would provide the flexibility of care (treatment and emergency short term respite care) that is so often needed, particularly for the profoundly handicapped. It is at times of crisis that parents most need help, and it is in these circumstances that the present pattern of care so often fails.

If the current philosophy of community care for the severely mentally handicapped child is to succeed then it is essential that a specific hospital resource is provided for them, and we as paediatricians should make the Department of Health and Social Security and local planners aware of this present lack of provision.

\section{Reference \\ ${ }^{1}$ MacFaul R. Medical care in severe mental handicap. Arch Dis Child 1986;61:533-5.}

S H Roussounis St James's University Hospital, Leeds LS9 7TF

\section{Head circumference charts updated}

Sir,

We have read with interest the report of Ounsted $e t$ al of a positive secular trend in head circumference from birth to 7 years. ${ }^{1}$ We also have found that mean head circumference during the first year is about $1 \mathrm{~cm}$ greater than that presented in standard growth charts ${ }^{23}$ and lies roughly on the 75 th centile of the reference values.
One hundred and twenty six babies born in Cambridge in 1984-85 were measured at four weekly intervals throughout their first year, and measurements are continuing into the second year. Birth weights were all more than $2500 \mathrm{~g}$ and gestational ages over 37 weeks. Altogether, $65 \%$ were breast fed to at least four months, and solids were introduced at a mean age of 3.3 months. Disposable paper tapes were used, which in preliminary measurements compared with a steel tape gave readings of plus $1 \mathrm{~mm}$, but the steel tape was considered unsuitable for use with young babies. Paper and fibreglass tapes, however, gave identical readings. The largest of two readings round the occipitofrontal circumference was taken.

The results, shown in the Table, are very similar to those

Table Head circumference from 2 weeks to 1 year

\begin{tabular}{lllll}
\hline $\begin{array}{l}\text { Age } \\
\text { (weeks) }\end{array}$ & No & $\begin{array}{l}\text { Boys } \\
\text { Mean }(S D)\end{array}$ & No & $\begin{array}{l}\text { Girls } \\
\text { Mean }(S D)\end{array}$ \\
\hline 2 & 36 & $36 \cdot 3(1 \cdot 3)$ & 24 & $36 \cdot 1(0 \cdot 9)$ \\
4 & 66 & $37 \cdot 8(1 \cdot 3)$ & 59 & $37 \cdot 3(1 \cdot 0)$ \\
8 & 67 & $39 \cdot 8(1 \cdot 2)$ & 58 & $39 \cdot 1(1 \cdot 0)$ \\
12 & 67 & $41 \cdot 1(1 \cdot 1)$ & 59 & $40 \cdot 2(1 \cdot 0)$ \\
16 & 67 & $42 \cdot 2(1 \cdot 1)$ & 59 & $41 \cdot 3(1 \cdot 1)$ \\
20 & 67 & $43 \cdot 2(1 \cdot 2)$ & 58 & $42 \cdot 2(1 \cdot 2)$ \\
24 & 67 & $44 \cdot 1(1 \cdot 1)$ & 58 & $43 \cdot 0(1 \cdot 2)$ \\
28 & 63 & $44 \cdot 9(1 \cdot 2)$ & 59 & $43 \cdot 8(1 \cdot 2)$ \\
32 & 67 & $45 \cdot 5(1 \cdot 2)$ & 59 & $44 \cdot 4(1 \cdot 2)$ \\
36 & 67 & $46 \cdot 1(1 \cdot 1)$ & 59 & $45 \cdot 0(1 \cdot 3)$ \\
40 & 66 & $46 \cdot 5(1 \cdot 1)$ & 59 & $45 \cdot 4(1 \cdot 3)$ \\
44 & 66 & $46 \cdot 9(1 \cdot 2)$ & 59 & $45 \cdot 8(1 \cdot 3)$ \\
48 & 64 & $47 \cdot 4(1 \cdot 1)$ & 59 & $46 \cdot 3(1 \cdot 3)$ \\
52 & 65 & $47 \cdot 7(1 \cdot 2)$ & 59 & $46 \cdot 6(1 \cdot 3)$ \\
\hline
\end{tabular}

of Ounsted et al. ${ }^{1}$ Although $57 \%$ of the babies came from the non-manual social classes (I, II, and IIIN), there were no differences between these babies and those in the manual social classes (IIIM, IV, and V).

Growth charts for infancy in current use in the United Kingdom include the Gairdner-Pearson charts ${ }^{2}$ as well as those of Tanner already discussed by Ounsted et al. ${ }^{1}$ For the head circumference centiles from birth at 40 weeks to 2 years Gairdner and Pearson used the classical Harvard data, which was collected between 1929 and 1939. The more recently published centiles of the National Center for Health Statistics, adopted for international use, also include data originating from $1929 .{ }^{3}$ We reiterate our plea that it is time that new charts were prepared for the present generation of babies to describe adequately the events that are taking place during this most rapid period of growth.

A A Paul, E A AHMED, and R G WhITEHEAD MRC Dunn Nutrition Unit, Cambridge CB4 $1 X J$ 